\title{
Gümüşhane Yöresi Kuşburnu (Rosa canina L.) ve Siyah Kuşburnu (Rosa pimpinellifolia L.) Meyvelerinin C Vitamini ve Şeker Analizleri
}

\author{
The Analysis of Sugar and Vitamin C in Rosehip (Rosa canina L.) and Black rosehip (Rosa \\ pimpinellifolia L.) Fruits of Gumushane Region
}

\author{
Mehmet ÖZ*1,a , Cemalettin BALTACI ${ }^{2, b}$, IIlhan DENIZ ${ }^{3, c}$ \\ ${ }^{I}$ Gümüşhane Üniversitesi, Gümüşhane Meslek Yüksekokulu, Ormancılık Bölümü, 29000, Gümüşhane \\ ${ }^{2}$ Gümüşhane Üniversitesi, Mühendislik ve Doğa Bilimleri Fakültesi, Gıda Mühendisliği Bölümü, 29000, Gümüşhane \\ ${ }^{2}$ Karadeniz Teknik Üniversitesi, Orman Fakültesi, Orman Endüstri Mühendisliği Bölümü, 61080, Trabzon
}

• Geliş tarihi / Received: 10.07.2017 • • Düzeltilerek geliş tarihi / Received in revised form: 12.02.2018 • Kabul tarihi / Accepted: 26.03 .2018

\begin{abstract}
$\ddot{O} z$
Ülkemizin önemli odun dışı orman ürünlerinden olan kuşburnu, tıbbı bitki ve gıda maddesi olarak kullanılmaktadır. Bu çalışmada, 2013 ve 2014 yıllarında Gümüşhane ilinde doğal olarak yetişen Kuşburnu (Rosa canina L.) ve Siyah kuşburnu (Rosa pimpinellifolia L.) meyve örneklerinin C vitamini ve şeker analizleri yıllara göre karşılaştırarak yapılmıştır. Örneklerin C vitamini analizleri, HPLC-UV cihazı kullanılarak ČSN EN 14130 metodu ile; şeker analizleri, HPLC-RID cihazı kullanılarak TS 13359 metoduna göre gerçekleştirildi. 2014 yılı siyah kuşburnu meyve örneklerindeki C vitamini miktarı $(305.92 \pm 2.45 \mathrm{mg} / 100 \mathrm{~g}), 2013$ yılı meyve örneklerinden $(199.90 \pm 2.11 \mathrm{mg} / 100 \mathrm{~g})$ daha fazla bulunmuştur. Kuşburnu meyvelerinde ise 2013 yılı örneklerindeki C vitamini miktarı (423.61 \pm 5.13 $\mathrm{mg} / 100 \mathrm{~g}), 2014$ yllı örneklerinden $(320.43 \pm 3.98 \mathrm{mg} / 100 \mathrm{~g})$ daha fazla olduğu tespit edilmiştir. Siyah kuşburnu ve kuşburnu meyveleri karşılaştıııldığında ise kuşburnu meyvelerinin $\mathrm{C}$ vitamini miktarları bu iki yılda da siyah

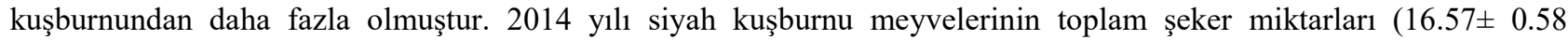
$\mathrm{g} / 100 \mathrm{~g}), 2013$ yllından $(11.01 \pm 0.66 \mathrm{~g} / 100 \mathrm{~g})$ daha fazla bulunmuştur. Kuşburnu meyvelerinde ise 2013 yll meyvelerindeki toplam şeker miktarı $(18.26 \pm 0.74 \mathrm{~g} / 100 \mathrm{~g}), 2014$ y1lından $(16.32 \pm 0.49 \mathrm{~g} / 100 \mathrm{~g})$ daha çok tespit edilmiştir. Her iki kuşburnu türü karşılaştırıldığında 2013 yılı meyvelerinin toplam şeker miktarı, kuşburnunda daha fazla iken 2014 yılı meyvelerinin toplam şeker miktarının ise siyah kuşburnunda daha fazla olduğu görülmüştür.
\end{abstract}

Anahtar kelimeler: Rosa canina L., Rosa pimpinellifolia L., C Vitamini, Şeker, Meyve

\begin{abstract}
Rosehip, one of the most important non-wood forest products of our country, is used as a medicinal plant and food material. In this study, vitamin $C$ and sugar analyzes of rosehip (Rosa canina L.) and black rosehip (Rosa pimpinellifolia L.) fruit samples naturally grown in Gumushane province in 2013 and 2014 were compared according to years. Vitamin $C$ analyzes of the samples were carried out by HPLC-UV instrument according to ČSN EN 14130; sugar analyzes were performed according to TS 13359 method using HPLC-RID device. The amount of vitamin C (305.92 $\pm 2.45 \mathrm{mg} / 100 \mathrm{~g})$ in black rosehip fruit sample grown in 2014 was found to be higher than that of the fruit samples $(199.90 \pm 2.11 \mathrm{mg} / 100 \mathrm{~g})$ grown in 2013. In the case of rosehip fruit, the amount of vitamin $C$ in the sample of the year $2013(423.61 \pm 5.13 \mathrm{mg} / 100 \mathrm{~g})$ was found to be higher than that the samples of the year $2014(320.43 \pm 3.98$ $\mathrm{mg} / 100 \mathrm{~g}$ ). When compared to black rosehip and rosehip fruits, the amount of vitamin $C$ of rosehip fruits is higher than black rosehip in these two years. The total sugar content $(16.57 \pm 0.58 \mathrm{~g} / 100 \mathrm{~g})$ of black rosehip fruits grown in 2014 was found to be higher than that of the year $2013(11.01 \pm 0.66 \mathrm{~g} / 100 \mathrm{~g})$. In the case of rosehip fruit, the total sugar content $(18.26 \pm 0.74 \mathrm{~g} / 100 \mathrm{~g})$ in the fruits of the year 2013 was found to be more than that of the year 2014 (16.32 \pm $0.49 \mathrm{mg} / 100 \mathrm{~g}$ ). When compared to both types of rosehips, it was revealed that the total sugar amount of the fruit samples grown in 2013 was higher in rosehip, while it was higher in black rosehip in 2014.
\end{abstract}

Keywords: Rosa canina L., Rosa pimpinellifolia L., Vitamin C, Sugar, Fruit

\footnotetext{
*a Mehmet ÖZ; mehmetoz@ gumushane.edu.tr; Tel: (0456) 2331060 - 2927; orcid.org/0000-0001-8392-4476

${ }^{\mathrm{b}}$ orcid.org/0000-0002-4336-4002 $\quad{ }^{\mathrm{c}}$ orcid.org/0000-0003-1821-5416
} 


\section{Giriş}

Ormanlardan üretilen tüm bitkisel, hayvansal ürünler ve mantarlar odun dışı orman ürünleri (ODOÜ) olarak bahsedilmektedir. Ayrıca ağaç işleyen sanayi sektörlerinde üretim sonucunda ortaya çıkan kabuklar, kozalaklar, çalılar, yongalar, kökler ve orman örtüsü de bu grup içerisinde bulunmaktadır.

Günümüze gelindiğinde ise Orman Genel Müdürlügü (OGM) odun dişı orman ürünlerini bitkisel kökenli, hayvansal kökenli ve mineraller olarak üç temel gruba ayırmıştır. Bunlar:

Reçine, sığla yağı, buhur, katran, mantar, salep vb. otsu bitkiler, geniş ve iğne yapraklar, çam fistığ 1 , meyve tohumları, meşe palamudu, meşe mazısı, bitkisel kabuklar hayvan yemi ve kökler, bitkisel kökenli ürünler sınıfına örnek olarak verilebilir. Hayvansal kökenli ürünler: Memeliler, kuşlar ve balıklar bu grubu oluş̧urmaktadır. Örnek olarak, orman içinde bulunan sularda yaşayan balık ve diğer su ürünlerinin yanında et, post, deri, vb. kısımlarından faydalandığımız yaban hayvanları ürünleri ve orman köylülerinin gıda ihtiyacı ile geçimine katkı sağlayan diğer ürünlerin bu grupta olduğu söylenebilir. Mineral Kökenli Ürünler: Sular, kumlar, çakıllar, taşlar ve madenler bu gruba örnek olarak verilebilir (OGM, 2008).

Bir başka tanımda ise orman işletmeciliği faaliyetleri neticesinde üretilen orman ürünleri, asli ve tali orman ürünleri olmak üzere iki fark1 grupta sınıflandırılmaktadır. Sözü edilen orman ürünlerinden asli ürünleri, ormandan elde edilen yapacak ve yakacak odunlar oluşturmaktadır. $\mathrm{Bu}$ sınıf da yer alan ürünlere sanayi odunları, yakacak odunlar, tomruklar, tel direkleri, kâğıtlık odunlar, maden direkleri, lif-yonga odunları ve sırıklar örnek olarak verilebilir. Ormanlardan elde edilen otsu bitkiler, çalı, ağaççık ve ağaç odunları dışında elde edilen uçucu yağlar, reçineler, meyveler, tohumlar, çiçekler, yapraklar, kabuklar, kökler, soğanlar, yumrular ve mantarlar ise tali ürünler sinıfina girmektedir (Kurt, 2011).

Kuşburnu türleri odun dışı bitkisel orman ürünleri sınıfında yer almaktadır. Bu çalışmanın amacı ülkemizde yayılış alanı olarak en çok bulunan kuşburnu türü olan Rosa canina L. (kuşburnu) ile daha az yayılışa sahip ve siyah renkli bir kuşburnu türü olan Rosa pimpinellifolia L. (siyah kuşburnu) türünü $\mathrm{C}$ vitamini ve şeker miktarı açısından karşılaş̧ırmaktır. $\mathrm{Bu}$ karşılaştırma yetişme yeri itibari ile farkı yerlerde bulunan iki ayrı kuşburnu türünde ve iki yıl üst üste yapılarak yıllara göre değişimi belirlemektir.

\subsection{Kuşburnu (Rosa ssp.)}

Kuşburnu Rosaceae familyasından Rosa cinsine ait çalı formunda, kışın yaprağını döken bir bitki türü olup anavatanı Batı Asya, Anadolu, Kuzey ve Orta Avrupa'dır. Kuşburnuna halk dilinde Yabangülü, Şillan, Deligül, Gülburnu, Gülelması da denilmektedir. "Rosaceae" familyasının dünya genelinde 200 takson, Türkiye'de doğal yayiliş yapan 25 takson ve Doğu Karadeniz Bölgesinde ise 17 adet doğal taksonu bulunmaktadır. Kuşburnu dünya üzerinde Avrupa, Asya ve Kuzeybatı Afrika'da doğal yayılış yapan kışın yaprağını döken bir çalı formunda bir bitkidir (Sarıbaş, 1996).

Gümüşhane ilinde ise doğal 11 takson yetişmektedir (Öz, 2016) Türkiye'de kuşburnunun yayılış miktarının 9.805 hektar potansiyel varlığının ise $1.396 .122 \mathrm{~kg}$ olduğu tahmin edilmektedir. (OGM, 2014). Tablo 1.'de Gümüşhane'de doğal olarak yetişen kuşburnu türleri gösterilmiştir (Öz, 2016).

Tablo 2. Gümüşhane'de doğal olarak yetişen kuşburnu türleri

\begin{tabular}{ll}
\hline \multicolumn{1}{c}{ Takson Adı } & \multicolumn{1}{c}{ Türkçe adı } \\
\hline Rosa pisiformis (Christ) D. Sosn. (Endemik) & Algül \\
Rosa hemisphaerica J.Herrm. & Kadı̈nöbeği \\
Rosa foetida J. Herrm & Sarıül, Acem sarısı \\
Rosa villosa L. subp. villosa L. & Sakız gülü \\
Rosa villosa L. subsp. mollis (SM.) Keller Et Gams & - \\
Rosa iberice Stev. in Bieb. & Gülezer \\
Rosa montana Chaix subsp. woronowii (Lonacz.) Ö. Nilsson & - \\
Rosa pimpinellifolia L. & Siyah kuşburnu \\
Rosa gallica L. & Kirmıż gül, Hokka gülü \\
Rosa pulverulenta Bieb. & Bodur gül \\
Rosa canina L. & Kuşburnu, Yabani gül \\
\hline
\end{tabular}




\subsection{Rosa canina L. (Kuşburnu)}

Rosa canina L. boyu $1.5-3.5 \mathrm{~m}$. yüksekliğinde olan çoğunlukla dalları geriye kıvrık, bazen tırmanıcı bazen dik çalı olan ve değişik şekilleri bulunan bir türdür. Dikenler büyükçe, geriye kıvrılır ve genişler. Yaprakçıkları koyu yeşil renkli olup, ortalama 5-7 tanedir ve şekilleri geniş yumurta biçiminden dar elipse kadar değişiklik gösterir. Çiçekler tekli bulunur ya da 2 ile 15 tanesi bir arada bulunurlar. Çiçeklenme zamanı mayıs-haziran ve temmuz aylarıdır. Kuşburnu 30$2500 \mathrm{~m}$. rakımları arasında orman açıklıklarında ve kayalık yamaçlarda yaygın olarak yetişir. Ülkemizin hemen her tarafinda Rosa canina L. türü bulunmaktadır. Kuşburnu ürünleri çay ve pekmez yapımında en çok kullanılan türdür (Kutbay ve Kılınç, 1996). Kuşburnu türleri arasında yayılışı ve meyve özellikleri bakımından işlenmeye en uygun türlerden biri de Rosa canina L.'dır (Anşin, 1996). Yöresel olarak: Yabani Gül, Köpek gülü, Askil, Civil, Gül Burnu, Gül Elması, İp Burmas1, İp burnu, İt Burnu, Kuşburnu, Kuşburni, Asker gülü, İt gülü şeklinde adlar almaktadır. Ülkemizde Rosa canina L.'nin dağılımı Şekil 1.'de verilmiştir (Öz, 2016). Rosa canina L.'nin taksonomik sıra düzeni aşağıdaki şekildedir:

* Bölüm: Magnoliophyta
* Sinıf: Magnoliopsida
* Altsınıf: Rosidae
* Takım: Rosales
* Familya: Rosaceae
* Cins: Rosa
* Tür: Rosa canina L.

\subsection{Rosa pimpinellifolia L. (Siyah Meyveli Kuşburnu)}

Siyah meyveli kuşburnu 1 m.'ye kadar boy yapabilen kısa boylu bir çalıdır. Diken sayısı çok fazla miktarda olup, dik veya hafifçe eğik şekildedir. Ortalama 7-11 adet oval şekilde yaprakçıkları vardır. Çiçekleri beyaz veya kremsi beyaz renkli olup sürgünlerde tek tek bulunurlar. Meyveleri ise morumsu siyah renklerde, küre seklinde yandan basık ve tüysüzdür. Çiçeklenme zamanı haziran ve temmuz aylarıdır. Rosa pimpinellifolia L. 1200-2750 m. rakımlarda kurak ve kayalık yamaçlarda, volkanik kayalar ya da kireçtaşı yapılı topraklarda yetişir. Yayılış alanları ise; Gümüşhane, Erzurum, Ağrı ve Van'dır (Kutbay ve Kılınç, 1996). Siyah kuşburnu türü kültüre alınarak 1slah edilmesi mümkün olan ve meyveleri işlenmeye en uygun türlerden biri olduğu belirtilmiştir (Anşin, 1996). Yöresel adları, siyah meyveli kuşburnu, siyah kuşburnu, koyungözü şeklindedir. Rosa pimpinellifolia L.'nin ülkemizdeki dağılımı Şekil 2.'de verildiği gibidir (Öz, 2016). Rosa pimpinellifolia L. nın taksonomik sıra düzeni şu şekildedir:

$\begin{array}{lll}\text { * Bölüm: } & \text { Magnoliophyta } \\ \text { * Sinıf: } & \text { Magnoliopsida } \\ \text { * Altsınıf: } & \text { Rosidae } \\ \text { * Takım: } & \text { Rosales } \\ \text { * Familya: } & \text { Rosaceae } \\ \text { * Cins: } & \text { Rosa } \\ \text { * Tür: } & \text { Rosa pimpinellifolia } \text { L. } \\ \text { * Sinonimi: } & \text { Rosa spinosissima L. }\end{array}$

\subsection{Kuşburnu Bitkisinin Kimyasal Bileşimi ve Kullanim Alanlart}

Kuşburnu besin değeri ve insan sağglığı açısından oldukça faydaları olan bir gıdadır. Kuşburnu, halk hekimliğinde farklı hastalıkların tedavisinde ilaç (drog) olarak en fazla kullanılan bitkilerdendir. Kuşburnu meyvelerinde $\mathrm{C}, \mathrm{P}, \mathrm{A}, \mathrm{B}_{1}, \mathrm{~B}_{2}$, E ve $\mathrm{K}$ vitaminleri vardır. Kuşburnu, meyvesi ile reçel, marmelat, meyve suyu, çay gibi ürünler üretilerek bu bitkiye emek harcayan kişilere gelir sağlamaktadır (Doğan vd., 2006). Kuşburnu antiinflamatuar olmasının yanı sıra, C vitamini ve likopen de içeren iyi bir bitkisel besin kaynă̆ıdır. Besleyici kompozisyonu nedeniyle, kuşburnu takviyesi, osteoartrit, romatoid artrit ve kanser dahil olmak üzere bazı kronik hastalıklarda çok olumlu etkilere sahiptir (Fan vd., 2014).

Yetişkin bir insanın günlük vitamin ve mineral ihtiyacı düşünüldüğünde kuşburnu nektarı ya da marmelat1, C vitamini ihtiyacinın tamamını ve diğer vitamin ve mineral ihtiyacının ise önemli bir kısmını karşılayacak düzeydedir (Yıldız ve Nergiz, 1996). Kuşburnu halk ilacı olarak böbrek ve mesane taşlarında, ishale, diş eti kanamalarına, yan ve göğüs ağrılarına karşı kullanılmaktadır.

Kuşburnu meyvelerinin bir başka kullanım alanı da içerdiği mineral maddeler (potasyum ve fosfor elementleri), vitaminler ile gida sanayinde meyve ve sebze sularının zenginleştirilmesi işlemidir. Kuşburnu yağının; cilt koruyucu, yaşlanmayı geciktirici, özellikle göz ve ağız çevresi kırışıklıkları önleyici, güneş ve sert hava etkisinden koruyucu, yaralanmış dokuları iyileştirici ve kalınlaştırıcı, hücre yenileyici gibi birçok faydası bulunmaktadır (Öz, 2016). 


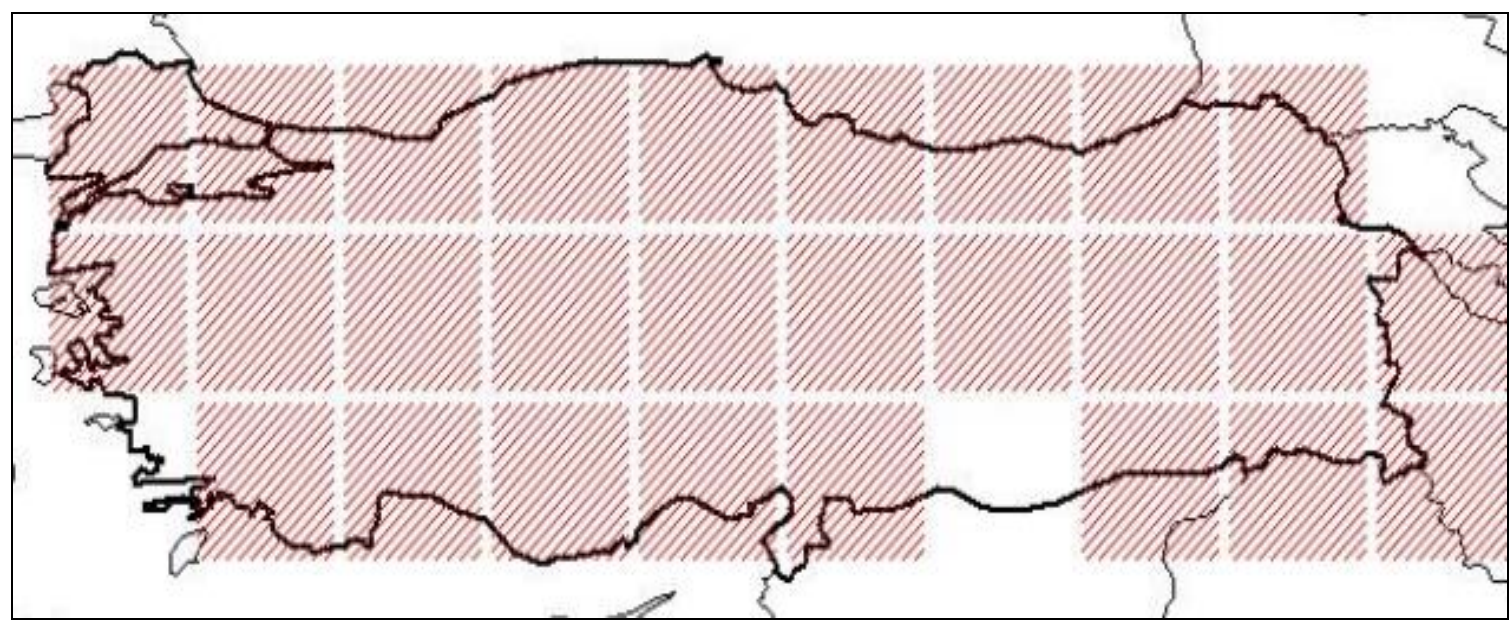

Şekil 1. Rosa canina L.'nin ülkemizdeki yayı11ı̧ı (Öz, 2016).

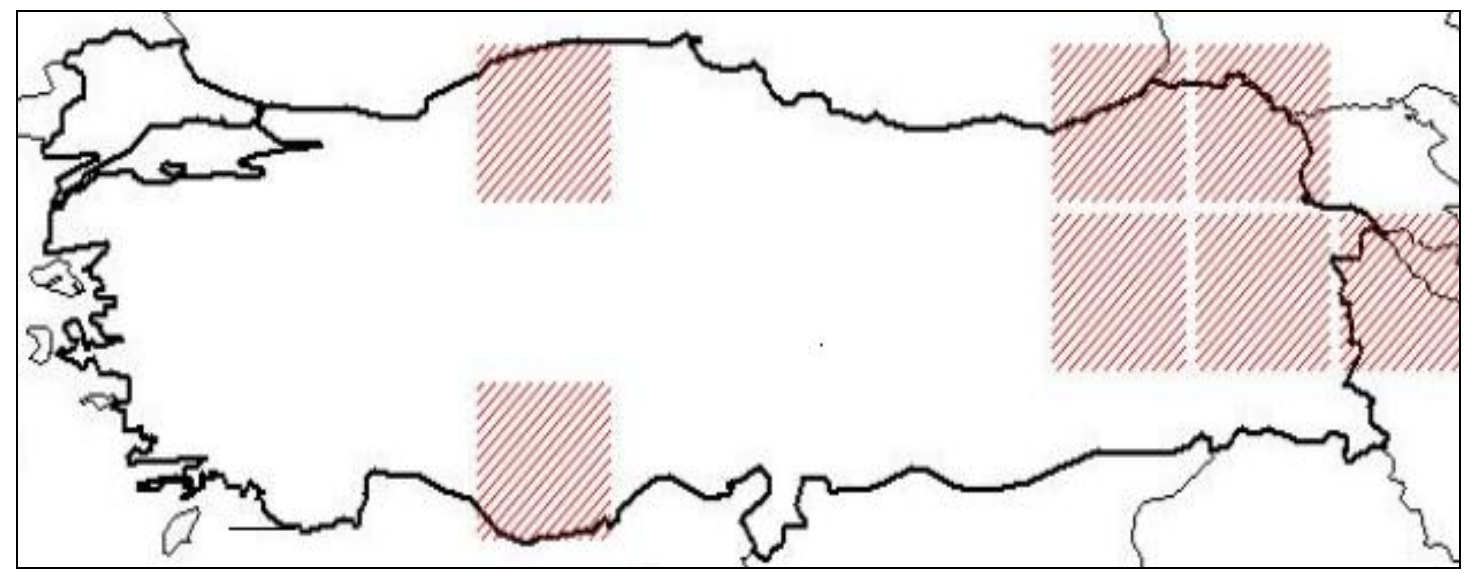

Şekil 2. Rosa pimpinellifolia L.'nin ülkemizdeki dağıllışı (Öz, 2016).

\section{Materyal ve Metod}

\subsection{Materyal}

İncelenen Kuşburnu türleri, Gümüşhane yöresinde doğal yayılış gösterdikleri yerlerden alındı. Kuşburnu (Rosa canina L.) türünün meyveleri 2013 ve 2014 y1lı Eylül ayında Gümüşhane, Torul, Köstere Köyü 1100 m rakımdan toplandı. Siyah meyveli kuşburnu (Rosa pimpinellifolia $\mathrm{L}$.) türünün meyveleri ise 2013 ve 2014 y1lı Ekim ayında Gümüşhane, Merkez, Kocayokuş Köyü $1800 \mathrm{~m}$ rakımdan aynı günlerde ve aynı bitkilerden toplandı. $\mathrm{Bu}$ türlerden en az 30 bitkiden örnekler alındı. Bitkilerin tür teşhisleri Karadeniz Teknik Üniversitesi, Orman Fakültesi, Kato Herbaryumu tarafindan yapıldı (Kato No:24436, Kato No: 24437). Toplanan örnekler analizler yapilıncaya kadar $-18{ }^{\circ} \mathrm{C}$ bekletildi. Alınan her iki türe ait örnekler ayrı ayrı birleştirilerek laboratuvar değirmeninde homojen hale getirildi. Analiz çalışmaları homojenleştirilmiş numunelerden yapıldı.

\subsection{Metod}

\subsubsection{Rosa canina $L$. ve Rosa pimpinellifolia $L$. meyvelerinin C vitamini Analizleri}

Numunelerin C vitamini analizleri HPLC-UV (yüksek basınç sıvı kromatografisi UV dedektör) metoduna göre Thermo separation products, UV 1000 dedektörlü HPLC-UV cihazı ile gerçekleştirildi. Kalibrasyon eğrisi için L-askorbik asitden, 10, 30, 60, 90 ve $120 \mathrm{mg} / \mathrm{L}$ 'lik konsantrasyonların standart çözeltileri hazırlandı. 2013 ve 2014 yillarında toplanan Rosa pimpinellifolia L. ve Rosa canina L. türlerinin meyvelerinden $10 \mathrm{~g}$ alındı ve parçalayıcıda parçalara ayrıldı. Parçalanmış meyvelerin üzerine $70 \mathrm{~mL}$ yeterli miktarda (üzerini kapatacak kadar) metafosforik asit $(\% 15 \mathrm{~m} / \mathrm{m})$ ilave edilerek homojenleştiricide karıştırıldı. Homojenleșen numuneler $100 \mathrm{~mL}$ 'ye tamamlanarak, filtre kâğıdından süzüldü. Süzüntüler 0,45 mikron filtreden geçirilerek viallere alındı ve HPLC cihazına verildi. $\mathrm{C}$ vitamini analizi için uygulanan 
HPLC koşulları Tablo 2.'de gösterilmiştir. Analizi yapılan $\mathrm{C}$ vitaminin numune içerisindeki miktarı kalibrasyon grafiği yöntemi $(y=9498,7 x+0)$ kullanılarak hesaplandı. Örneklerden Rosa canina L.'ye ait C vitamin HPLC-UV kromotogram1 Şekil 3.'de gösterilmiştir.

Tablo 2. Uygulanan yöntemin HPLC koşulları

\begin{tabular}{lcl}
\hline HPLC sistemi & $:$ & Thermo separation products, UV 1000 dedektör \\
Kolon & $:$ & Supelcosil C18,5 $\mu \mathrm{m},(25 \times 4,6 \mathrm{~mm})$ \\
Mobil sistem & $:$ & Gradient \\
Mobil faz C & $:$ & Metanol $-\mathrm{H}_{2} \mathrm{O}(5: 95, v / v) \mathrm{pH}=3.00(\mathrm{H} 3 \mathrm{PO} 4)$ \\
Kolon sicaklığ1 & $:$ & $20{ }^{\circ} \mathrm{C}$ \\
İnjeksiyon hacmi : & $20 \mu \mathrm{l}$ \\
Dalga boyu & $:$ & $254 \mathrm{~nm}(210-360 \mathrm{~nm}$ arası) \\
Akış Hızı & $:$ & $1.0 \mathrm{ml} / \mathrm{dk}$ \\
\hline
\end{tabular}

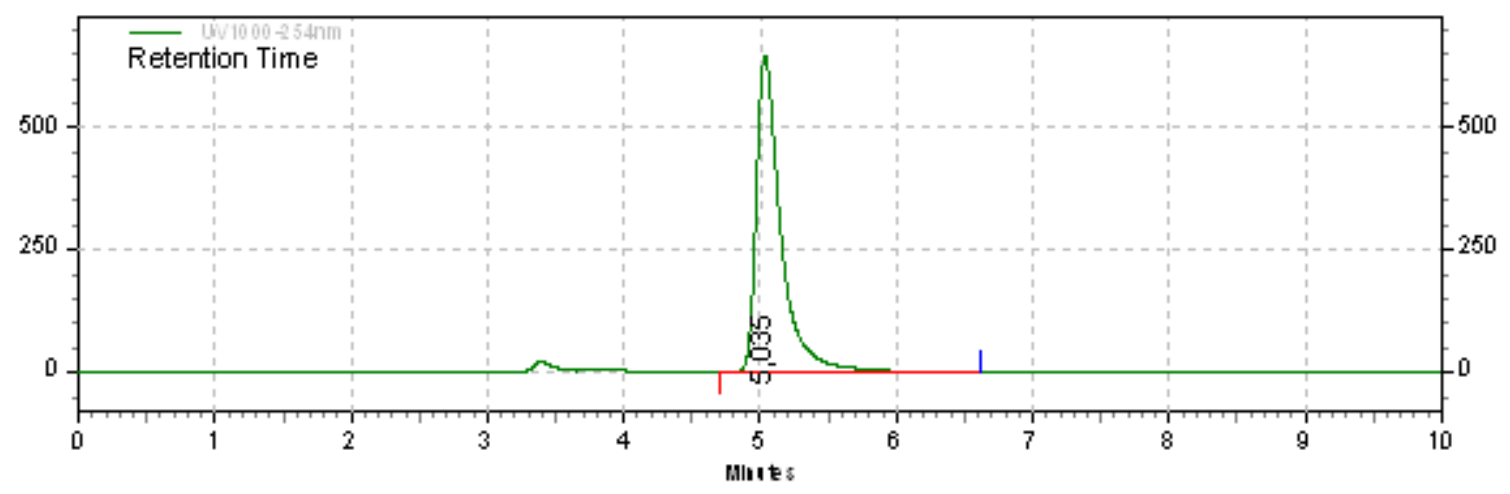

Şekil 3. C vitamini HPLC-UV kromotogramı

\subsubsection{Rosa canina $L$. ve Rosa pimpinellifolia $L$. Meyvelerinin Şeker Analizleri}

Numunelerin şeker analizleri TS 13359 metoduna göre ve Agilent 1260 infinity marka, dörtlü pompaya sahip, oto enjektörlü HPLC-RID cihazında gerçekleştirildi. 2013 ve 2014 yıllarında toplanan Rosa pimpinellifolia L. ve Rosa canina L. türlerinin meyvelerinden 2,5 gr alındı ve parçalayıcıda parçalara ayrıldı. Parçalanmış meyvelerin üzerine $25 \mathrm{ml}$ ultra saf su ilave edilerek homojenleştiricide karıştırıldı. Homojenleşen numuneler $50 \mathrm{ml}$ 'ye ultra saf su ile tamamlanarak filtre kâğıdından süzüldü. Süzüntüler 0,45 mikron filtreden geçirilerek viallere alındı ve HPLC cihazına verildi. Şeker analizi için uygulanan HPLC koşulları Tablo 3.'de verilmiştir.

Analizi yapılan fruktoz, glukoz ve sakkarozun numune içerisindeki miktarı kalibrasyon grafiği yöntemi (fruktoz için $y=98,4 x+130$, glukoz için $\mathrm{y}=57,2 \mathrm{x}+95$, sakkaroz için $\mathrm{y}=12,4 \mathrm{x}+$ 47 ) kullanılarak hesapland. Örneklerden Rosa pimpinellifolia L.'ye ait fruktoz, glukoz ve sakkaroz HPLC-RID kromotogramları Şekil 4.'de verilmiştir.

Tablo 3. Uygulanan yöntemin HPLC koşulları

\begin{tabular}{lcl}
\hline HPLC sistemi & $:$ & Agilent 1260 RID Dedektörlü HPLC \\
Kolon & $:$ & Supelcosil C18, $5 \mu \mathrm{m},(25 \times 4,6 \mathrm{~mm})$ \\
Mobil sistem & $:$ & Gradient \\
Mobil faz C & $:$ & Asetonitril- $\mathrm{H}_{2} \mathrm{O}(80-20)$ \\
Kolon sıcaklığ1 & $:$ & $20{ }^{\circ} \mathrm{C}$ \\
İnjeksiyon hacmi : & $20 \mu \mathrm{l}$ \\
Akış Hız & $:$ & $1.2 \mathrm{ml} / \mathrm{dk}$ \\
\hline
\end{tabular}

\section{Bulgular ve Tartışma}

\subsection{C vitamini Analizi Sonuçlart}

2013 ve 2014 yıllarında toplanan kuşburnu (Rosa canina L.) ve siyah kuşburnu (Rosa pimpinellifolia L.) ya ait incelenen meyve örneklerindeki C vitamini miktarları Tablo 4.' de gösterilmiştir. 


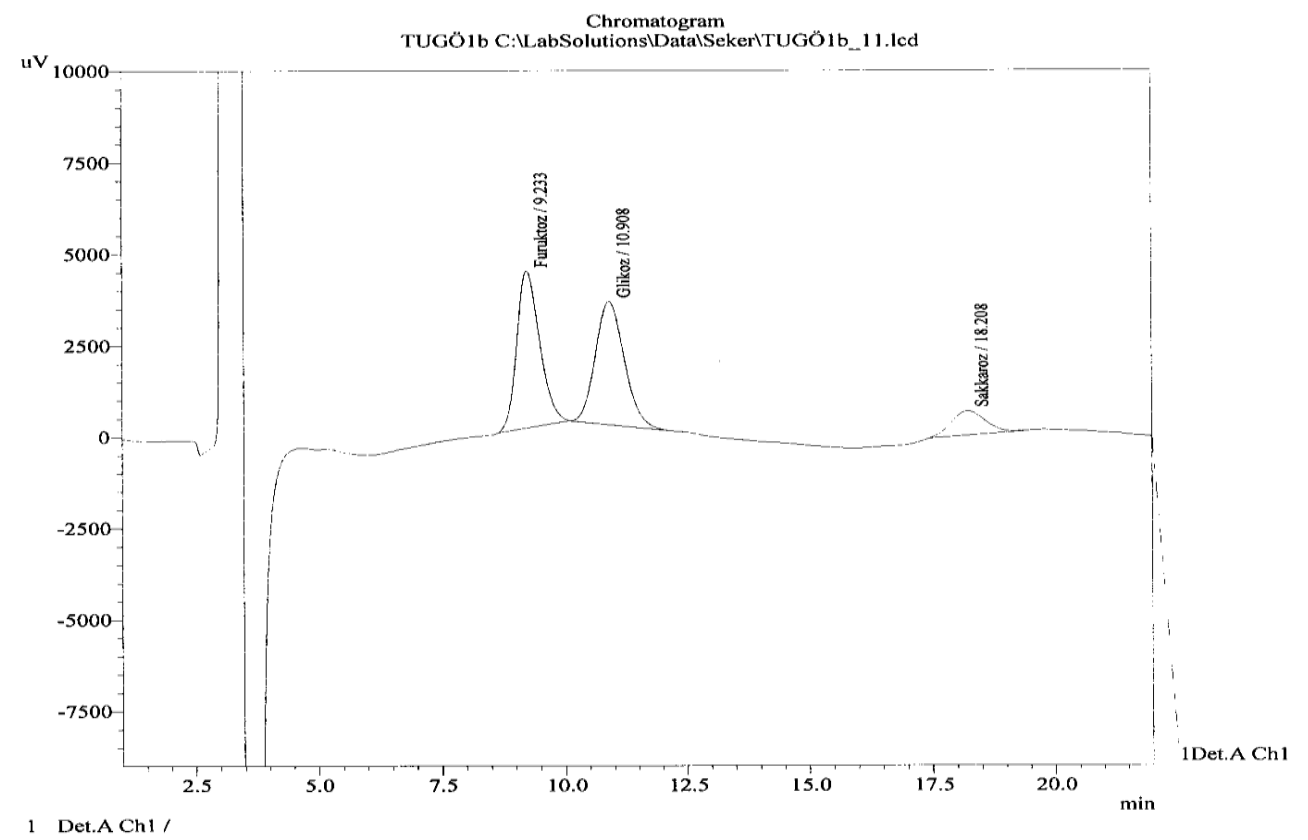

Şekil 4. Sakkaroz, fruktoz ve glikoz HPLC-RID kromotogramları

Tablo 4. Kuşburnu (Rosa canina L.) ve siyah kuşburnu (Rosa pimpinellifolia L.) meyve örneklerindeki C vitamini miktarlar1*

\begin{tabular}{lllll}
\hline & \multicolumn{2}{l}{ Rosa canina $\mathrm{L}}$. & \multicolumn{2}{l}{ Rosa pimpinellifolia L. } \\
\cline { 2 - 5 } & 2013 & 2014 & 2013 & 2014 \\
\cline { 2 - 5 } $\begin{array}{l}\text { C vitamini miktar1 } \\
(\mathrm{mg} / 100 \mathrm{~g})\end{array}$ & $423.61 \pm 5.13$ & $320.43 \pm 3.98$ & $199.90 \pm 2.11$ & $305.92 \pm 2.45$ \\
\hline
\end{tabular}

* Değerler üç paralel ölçümün ortalamasıdır

Siyah kuşburnu 2014 y1lı meyvelerindeki C vitamini miktarı, 2013 y1lındaki meyvelerinden daha fazla bulunmuştur. Kuşburnu meyvelerinde ise 2013 yilında toplanan örnekteki C vitamini miktarı 2014 y1lından daha fazla tespit edilmiștir. Siyah kuşburnu ve kuşburnu meyveleri karşılaştırıldığında ise kuşburnu meyvelerinin C vitamini miktarları her iki yılda da siyah kuşburnundan daha fazladır. Yıllara göre karşılaştırma yapıldı ğında, kuşburnu türünde 2014 y1lında 2013 yılına göre bir azalma meydana gelmiş, ancak siyah kuşburnu türünde ise 2014 yılında $C$ vitamini miktarında artış olmuştur.

Murathan vd. (2016) Ardahan ilinden topladıkları $R$. pimpinellifolia, $R$. villosa, $R$. canina ve $R$. dumalis ile yaptıkları çalışmalarında askorbik asit (C vitamini) miktarını siras1 ile $24.93 \pm 4.0$, $119.83 \pm 3.3,754.48 \pm 100.2,254.81 \pm 12.5 \mathrm{mg} / 100 \mathrm{~g}$ olduğunu rapor etmişlerdir. Abacı vd. (2016) Rosa iberica STEV. ile yaptıkları araştırmada askorbik asit (C vitamini) miktarın $503.26 \pm 18.8 \mathrm{mg} / 100 \mathrm{~g}$ olduğunu belirtmişlerdir.
Kazaz vd. (2009) Rosa damascena Mill. ve Rosa canina $\mathrm{L}$. meyveleri ile yaptıkları araştırmada $\mathrm{C}$ vitamini miktarlarını Rosa canina $\mathrm{L}$. meyvesinde $411.0 \mathrm{mg} / 100 \mathrm{~g}, \quad$ Rosa damascena Mill. meyvesinde ise $332.0 \mathrm{mg} / 100 \mathrm{~g}$ olarak bulmuştur. Fan vd. (2014) kuşburnunun besin değerleri hakkında yaptıkları araştırmalarında $\mathrm{C}$ vitamini miktarını $426 \mathrm{~m} / 100 \mathrm{~g}$ olarak belirtmişlerdir.

Dölek, (2013) çalışmasında ülkemizde kuşburnu üzerine yapılan araştırmalarda en yüksek $C$ vitamini değerlerinin $1074 \mathrm{mg} / 100 \mathrm{~g}$ ile 2962 $\mathrm{mg} / 100 \mathrm{~g}$ arasında (Ercişli vd., 2001), en düşük C vitamini değerlerinin ise $12.04-43.77 \mathrm{mg} / 100 \mathrm{~g}$ arasında (Türkben vd., 2010) olduğunu beyan etmiştir.

Ropciuc vd. (2011) Rosa canina L. meyvelerindeki askorbik asit içeriği ( $\mathrm{C}$ vitamini) ile ilgili yaptıkları çalışmada kaydedilen değerleri 347.12 ile $621.31 \mathrm{mg} / 100 \mathrm{~g}$ arasında değiştiğini ve bu değişikliğin sebebini ise yükseklik, toprak tipi, nem ile ilgili olduğunu bildirmişlerdir. 
Kara ve Oktay (2008) tarafından çeşitli sebze ve meyvelerin tespit edilmiş $\mathrm{C}$ vitamini değerleri karşılaştırıldığında $100 \mathrm{~g}$ maydanozda $180 \mathrm{mg}$, yeşil sivri biberde $100 \mathrm{mg}$, limonda $50 \mathrm{mg}$, mandalinada $30 \mathrm{mg}$, narda $10 \mathrm{mg}$ askorbik asit bulunduğu rapor etmiştir (Kara ve Okyay, 2008; Kubat vd., 2013). Kuşburnu meyvelerinin C vitamini analizleri hakkında yapılan çalışmalar göz önüne alındığında bulunan sonuçların literatürdeki bilgilerle aynı doğrultuda olduğunu bize göstermektedir.

\section{2. Şeker Analizi Sonuçlart}

2013 ve 2014 yıllarında toplanan kuşburnu (Rosa canina L.) ve siyah kuşburnu (Rosa pimpinellifolia L.) ya ait incelenen meyve örneklerindeki şeker miktarları, Tablo 5.' de gösterilmiştir.

Tablo 5.'de verilen toplam şeker miktarları değerlendirildiğinde siyah kuşburnu meyvelerinin 2014 y1lı değerleri 2013 y1lından daha fazla bulunmuştur. Kuşburnu meyvelerinde ise 2013 y1lı meyvelerindeki toplam şeker oranı 2014 yılından daha çok tespit edilmiştir. Her iki kuşburnu türü karşılaştırıldığında ise 2013 yılı meyvelerinin toplam şeker oranı kuşburnunda daha çok iken 2014 yılı verilerinde siyah kuşburnu miktarı daha fazla belirlenmiştir. Yı1lara göre karşılaştırma yapıldığında, kuşburnu türünde 2014 y1lında 2013 y1lına göre bir azalma meydana gelmiş, ancak siyah kuşburnu türünde ise 2014 yılında toplam şeker miktarında artış olmuştur.

Tablo 5. Kuşburnu (Rosa canina L.) ve siyah kuşburnu (Rosa pimpinellifolia L.) meyve örneklerindeki şeker miktarları*

\begin{tabular}{lllll}
\hline & \multicolumn{2}{l}{ Rosa canina $\mathrm{L}}$. & \multicolumn{2}{l}{ Rosa pimpinellifolia $\mathrm{L}}$. \\
\cline { 2 - 5 } & 2013 & 2014 & 2013 & 2014 \\
\cline { 2 - 5 } Fruktoz $(\mathrm{g} / 100 \mathrm{~g})$ & $9.21 \pm 0.83$ & $9.06 \pm 1.18$ & $5.53 \pm 0.25$ & $8.32 \pm 1.71$ \\
Glukoz $(\mathrm{g} / 100 \mathrm{~g})$ & $9.02 \pm 1.24$ & $7.23 \pm 2.03$ & $5.41 \pm 0.63$ & $8.19 \pm 0.92$ \\
Sakkaroz $(\mathrm{g} / 100 \mathrm{~g})$ & $0.04 \pm 0.12$ & $0.02 \pm 0.21$ & $0.07 \pm 0.18$ & $0.06 \pm 0.16$ \\
\hline Toplam Şeker $(\mathrm{g} / 100 \mathrm{~g})$ & $18.26 \pm 0.74$ & $16.32 \pm 0.49$ & $11.01 \pm 0.66$ & $16.57 \pm 0.58$ \\
\hline
\end{tabular}

* Değerler üç paralel ölçümün ortalamasıdır

Murathan vd. (2016) R. pimpinellifolia, R. villosa, $R$. canina ve $R$. dumalis ile yaptıklar1 çalışmalarında, fruktoz miktarını sırası ile 4.38 4.90 - 5.03 - $4.15 \mathrm{~g} / 100 \mathrm{~g}$, glukoz miktarın 5.99 $12.48-8.05-6.79 \mathrm{~g} / 100 \mathrm{~g}$, sakkaroz miktarını ise $0.38-0.42-0.55-0.41 \mathrm{~g} / 100 \mathrm{~g}$ ve toplam şeker miktarının 14.92 - 24.05 - 18.78 - $15.29 \mathrm{~g} / 100 \mathrm{~g}$ olduğunu rapor etmişlerdir. Abac1 vd. (2016) Rosa iberica STEV. ile yaptıkları araştırmada fruktoz oranın $18.58 \pm 0 \mathrm{~g} / 100 \mathrm{~g}$, glukoz oranın $19.35 \pm 0.05$ $\mathrm{g} / 100 \mathrm{~g}$, sakkaroz oranın $0.49 \pm 0 \mathrm{~g} / 100 \mathrm{~g}$ ve toplam şeker oranını ise $26.74 \pm 0.12 \mathrm{~g} / 100 \mathrm{~g}$ olduğunu bildirmişlerdir.

Demir vd. (2014) Gümüşhane ilinden topladıkları $R$. canina, $R$. dumalis, $R$. gallica, $R$. dumalis subsp. Boissieri ve $R$. hirtissima. türleri ile yaptıkları analizlerde fruktoz miktarının sırası ile $18.84 \pm 2.40,10.78 \pm 0.80,17.11 \pm 2.37,16.15 \pm 0.65$, $13.12 \pm 1.48 \mathrm{~g} / 100 \mathrm{~g}$ ve glukoz miktarının ise $17.11 \pm 2.78,9.54 \pm 0.55,17.25 \pm 0.93,14.46 \pm 0.63$, $11.20 \pm 0.97 \mathrm{~g} / 100 \mathrm{~g}$ olduğunu belirtmişlerdir.
Özrenk vd. (2012) çalışmalarında, Erzincan bölgesinde doğal olarak yetişen kuşburnu meyvelerinde 15 farklı genotipe ait olgun meyvelerde yaptıkları analizlerde fruktoz oranını 7.96-14.76 g/100g, glukoz oranını 8.06-12.94 $\mathrm{g} / 100 \mathrm{~g}$ ve sakkaroz oranını ise $0.17-0.88 \mathrm{~g} / 100 \mathrm{~g}$ değerleri arasında bulunduğu bildirmiştir. Barros vd. (2011) Rosa canina L. ile yaptıkları araştırmalarında, olgunlaşmış meyvelerdeki fruktoz miktarını $8.89 \pm 0.06$, glukoz miktarını $7.46 \pm 0.02$, sakkaroz miktarın ise $3.77 \pm 0.32$ ve toplam şeker miktarını $20.46 \pm 0.24 \mathrm{~g} / 100 \mathrm{~g}$ olduğunu belirtmişlerdir.

Efe ve Doğruluk (2014) altın çilek bitkisi ile yaptıkları çalışmalarında, altın çilek meyve özsuyundaki toplam şeker içeriğini $4.9 \mathrm{~g} / 100 \mathrm{~g}$, diğer meyve özsularında ise toplam şeker oranını ise; armutta \%9.8, portakalda \%7.0, elmada $\% 11.1$ şeftalide $\% 8.5$ ve çilekte $\% 5.7$ olarak belirtmişlerdir. Kuşburnu meylerinde tespit edilen şeker oranlarının, diğer kuşburnu türleri ile 
yapılan çalışmalarda elde edilen sonuçlara ve çeşitli meyvelerle yapılan çalışmalarda bulunan sonuçlara benzer değerlerde olduğu anlaşılmaktadır.

\section{Sonuç ve Öneriler}

Bitkisel odun dışı orman ürünleri açısından ülkemiz çok zengin bir varlığa sahiptir. $\mathrm{Bu}$ kaynakların kullanım oranları ise her geçen artış göstermektedir. Ülkemiz orman alanlarında bulunan bu bitkilerin çeşit ve miktarının tespit edilmesi ve değerlendirme olanaklarının çoğaltılması, ekonomik, sosyal yönden oldukça faydalı olacağı düşünülmektedir.

Yapılan bu çalışmada, türler birbiri ile kıyaslandığında kuşburnu türü meyvelerinin C vitamini değerleri, siyah kuşburnu türüne göre her iki yılda da fazla bulunmuştur. Şeker analizi sonuçları karşılaştırıldığında ise 2013 yılı meyvelerinin toplam şeker oranı kuşburnunda daha çok iken 2014 yılı verilerinde siyah kuşburnu toplam şeker miktarının daha fazla olduğu belirlenmiştir. Yıllar itibariyle kıyaslandığında kuşburnu türünün 2013 yılında toplanan meyvelerinin $\mathrm{C}$ vitamini ve toplam şeker analizi değerleri 2014 yılına göre daha fazla bulunurken, siyah kuşburnu türünde ise 2014 y1lında toplanan meyvelerinin $\mathrm{C}$ vitamini ve toplam şeker analiz değerleri 2013 y1lından daha fazla olduğu tespit edilmiştir.

Türlerin birbirleri arasında ve türlerin kendi arasında her iki ayrı yılda ortaya çıkan bu farklılıkların sebebi olarak bitkilerin genetik yapıs1, bitkilerin yaşı, yetişme yeri, toprak yapısı, iklim, yağış gibi iç ve diş etmenler sayılabilir. Yukarıda bahsedilen etmenlerden hangisinin, $\mathrm{C}$ vitamini veya şeker değerlerini artırıcı ya da azaltıcı yönde etkisinin olduğu araştırılması önerilebilir. Gümüşhane yöresinde doğal olarak yetişen kuşburnu taksonlarına ait meyvelerin, şeker ve $C$ vitamini miktarlarının belirlenmesi ile daha sonra yapılacak olan araştırmalara literatür oluşturması açısından oldukça önemli olduğu düşünülmektedir. $\mathrm{Bu}$ çalışma ayrıca kuşburnu meyvelerinin sağlık açısından ne kadar önemli olduğunun anlaşılmasına da önemli katkılar sağlayacaktır.

\section{Kaynaklar}

Abac1, Z.T., Zarıfikhosroshahı, M., Kafkas, E. ve Sevindik, E., 2016. Chemical Composition, Volatiles, and Antioxidant Activity of Rosa iberica STEV. Hips. Acta Scientiarum Polonorum Hortorum Cultus, 15, 1, 41-54.

Anşin, R., 1996. Doğu Karadeniz Bölgesinde Yetişen Doğal Rosa L. Taksonları. Kuşburnu Sempozyumu, 5-6 Eylül 1996, Gümüşhane, Türkiye, s.85-95.

Barros, L., Carvalho, A. M. ve Ferreira, I.C.F.R., 2011. Exotic fruits as a source of important phytochemicals: Improving the traditional use of Rosa canina fruits in Portugal. Food Research International, 44, 2233-2236.

Demir, N., Yildiz, O., Alpaslan, M. ve Hayaloglu, A.A., 2014. Evaluation of volatiles, phenolic compounds and antioxidant activities of rose hip (Rosa L.) fruits in Turkey. LWT - Food Science and Technology, 57, 126-133.

Determination of vitamin $\mathrm{C}$ in beverages, fruits and vegetables by HPLC/UV method (accredited SZPI method A/11, ČSN EN 14130).

Doğan, A., Kazankaya, A., Çelik, F. ve Uyak, C., 2006. Kuşburnunun Halk Hekimliğindeki Yeri ve Bünyesindeki Bileşenler Açısından Yararları. II. Ulusal Üzümsü Meyveler Sempozyumu, 14-16 Eylül 2006, Tokat, Türkiye, s.45-53.

Dölek, Ü., 2013. Bazı Kuşburnu (Rosa sp.) Türlerinde Optimal Hasat Zamanının ve Fitokimyasal Değişimlerinin Belirlenmesi. Doktora Tezi, Gaziosmanpaşa Üniversitesi Fen Bilimleri Enstitüsü. Tokat, 113s.

Efe, L. ve Doğruluk, E., 2014. Altın Çilek (Physalis peruviana L.) Bitkisinin Beslenme ve Tipta Kullanım Olanakları. II. Tibbi ve Aromatik Bitkiler Sempozyumu, 23-25 Eylül 2014, Yalova, Türkiye, s.378384.

Ercişli, S., Eşitken, A. ve Güleryüz, M., 2001. Erzurum (Merkez İlçe), Tortum, Pazaryolu ve Pasinler İlçelerinde Doğal Olarak Yetişen Kuşburnuların (Rosa spp.) Seleksiyon Yoluyla Islahı Üzerine Bir Araştırma. Bahçe Dergisi, 29 (1-2), 39-44.

Fan, C., Pacier, C. ve Martirosyan., D. M., 2014. Rose hip (Rosa canina L): A functional food perspective. Functional Foods in Health and Disease, 4, 11, 493-509. 
Kara, C. ve Okyay N., 2008. Bazı Meyve ve Sebzelerde C Vitamini Tayini, Tübitak Eğitimde Bilim Danışmanlığı Projesi. Fen ve Teknoloji Öğretmenleri Bilim Danışmanlığı ve Eğitimi Yönünden Destekleme Çalıştayı, 14-20 Haziran, Kayseri, Türkiye.

Kazaz, S., Baydar H. ve Erbaş, S., 2009. Variations in chemical compositions of Rosa damascena Mill. and Rosa canina L. Fruits. Czech Journal of Food Sciences, 27, 3, 178-184.

Kubat, A, Özaslan M, Karaduman A., Karagöz I, D. ve Kilıç, İ. H., 2013. C Vitamini Bakımından Zengin Sebze ve Meyvelerin Beyaz Kan Hücreleri Artışı Üzerine Etkilerinin Araştırılması. Adana Veteriner Kontrol ve Araştırma Enstitüsü (AVKAE) Dergisi, 3, 1, 31-37.

Kurt, R., 2011. Türkiye Odun D1şı Orman Ürünlerinin Mevcut Durumu ve Diş Ticaret Analizi. Yüksek Lisans Tezi, Bartın Üniversitesi Fen Bilimleri Enstitüsü. Bartın, $161 \mathrm{~s}$.

Kutbay, H,G. ve Kılınç, M., 1996. Kuşburnu (Rosa. L.) Türlerinin Taksonomik Özellikleri ve Türkiye'deki Yayılışları. Kuşburnu Sempozyumu, 5-6 Eylül 1996, Gümüşhane, Türkiye, s.75-83.

Murathan, Z.T., Zarıfikhosroshahı, M., Kafkas, E. ve Sevindik, E., 2016. Characterization of Bioactive Compounds In Rosehip Species From East Anatolia Region of Turkey. Italian Journal of Food Science, 28, 314325 .

O.G.M., 2008. Orman Genel Müdürlüğü Sürdürülebilir Orman Yönetimi Kriter ve Göstergeleri 2008 Y1lı Raporu, Ankara, 69s.

O.G.M., 2014. Orman Genel Müdürlüğü 2013 Y11 İdare Faaliyet Raporu, Strateji Geliştirme Dairesi Başkanlığ1, Ankara, 37s.
Öz, M., 2016. Rosa pimpinellifolia L. ve Rosa canina L. Kuşburnu Türlerinin Çiçek, Yaprak, Gövde ve Meyvelerinde Uçucu Yağ Analizleri ve Biyolojik Aktiviteleri. Doktora Tezi, Karadeniz Teknik Üniversitesi Fen Bilimleri Enstitüsü, Trabzon, 192s.

Özrenk, K., Gündoğdu, M. ve Doğan, A., 2012. Erzincan Yöresi Kuşburnu (Rosa canina L.) Meyvelerinin Organik Asit, Şeker ve Mineral Madde İçerikleri. Yüzüncü Y1l Üniversitesi Tarım Bilimleri Dergisi, 22, 1, 20-25.

Ropciuc, S., Cenuşă, R., Căpriţă, R. ve Crețescu, I., 2011. Study on the Ascorbic Acid Content of rose Hip fruit Depending on Stationary Conditions. Scientific Papers Animal Science and Biotechnologies, 44, 2, 129-132.

Sarıbaş, M., 1996. Batı Karadeniz Bölgesinde Doğal Yayılış Yapan Rosa canina L. (Kuşburnu) nun Bazı Morfolojik Palinolojik ve Tohum Özellikleri. Kuşburnu Sempozyumu, 5-6 Eylül 1996, Gümüşhane, Türkiye, s.65-74.

Türkben, C., Uylaşer V., İncedayı B. ve Çelikkol I., 2010. Effects of different maturity periods and processes on nutritional components of rosehip (Rosa canina L.), Journal of Food, Agriculture \& Environment, 8, 1, 26-30.

TS 13359, Bal-Fruktoz, Glukoz, Sakaroz, Turanoz ve Maltoz Muhtevası Tayini- Yüksek Performanslı Siv1 Kromatografisi (HPLC) Metodu, 2008, Ankara.

Y1ldı, H. ve Nergiz, C., 1996. Bir gıda maddesi olarak kuşburnu. Kuşburnu Sempozyumu, 5-6 Eylül 1996, Gümüşhane, Türkiye, s.309-318. 